\title{
RELAÇÕES VISÍVEIS ENTRE PELE E PSIQUISMO: UM ENTENDIMENTO PSICANALÍTICO
}

\author{
Hericka Zogbi J. Dias* \\ Rachel Rubin** \\ Alessandro Valério Dias ${ }^{* * *}$ \\ Gabriel José Chittó Gauer****
}

Resumo

O presente artigo aborda o estudo do adoecimento da pele no seu aspecto relacional. Para isto, percorreremos o caminho da construção do ego, enfocando o aspecto relacional eminentemente presente, através das teorias de Winnicott, Anzieu e McDougall. Abordaremos essa construção relacional do ego que se dá pela via do corpo, sobre o qual se imprimem os primeiros registros afetivos, e discutiremos, especialmente, a pele como órgão de relação.

Palavras-chave: pele, relaçóes objetais, psicossomática

\section{AbSTRACT}

VISIBLE RELATIONS BETWEEN SKIN AND PSYCHISM: A PSYCHOANALYTICAL APPROACH

This article approaches the study of skin illnesses in their relational aspects. To achieve that, we walk the path of ego building, focusing on the relational aspect imminently present,

* Psicóloga; Psicoterapeuta; Doutoranda em Psicologia pela Pontifícia Universidade Católica do Rio Grande do Sul (PUCRS); Bolsista CNPq.

** Graduanda em Psicologia pela Pontifícia Universidade Católica do Rio Grande do Sul (PUCRS); Bolsista de Pesquisa PIBIC/CNPq - PUCRS.

*** Mestrando em Psicologia pela Pontifícia Universidade Católica do Rio Grande do Sul (PUCRS).

**** Psiquiatra; Professor Adjunto Faculdade de Psicologia e Programas de Pós-Graduação em Psicologia e Gerontologia Biomédica da Pontifícia Universidade Católica do Rio Grande do Sul (PUCRS). 
through the theories of Winnicott, Anzieu and McDougall. We approach the relational construction of the ego that occurs by the way of the body, on which the first affective records are printed, particularly discussing the skin as a relational organ.

Keywords: skin, object relations, psychosomatic

\section{INTRODUÇÃO}

A relação do indivíduo com seu mundo interno e externo pode ser verificada na qualidade e característica das relaçôes estabelecidas ao longo da vida. As primeiras relações estabelecidas com objetos se dão no nível corporal (alimentação, cuidados, o toque na pele do bebê, reconhecimento do ambiente, e assim por diante). A criança pequena inicialmente faz o reconhecimento de seu mundo através do corpo, construindo a partir dele seu mundo interno em relação com o mundo e os objetos externos, posteriormente internalizados. Freud (1923/1976) afirma que o ego é, primeiro e acima de tudo, um ego corporal, não sendo simplesmente uma entidade de superfície, mas, ele próprio, a projeção de uma superfície.

A forma como se dá a estruturação do ego é foco de muitas teorizaçōes psicanalíticas e, mesmo que não destacado em todas elas, é uma estruturação que tem o corpo como veículo. Muito dessa estruturação se dá pelo contato com o outro, que acontece, em primeiro lugar, pela pele - parafraseando Anzieu (1989), que será melhor explorado adiante -, uma superfície em que o mundo externo e interno imprimem seus conflitos.

O tema relações objetais pressupõe, a priori, relação, muito embora seja freqüentemente reduzido ao termo em si mesmo. A conceituação de relações objetais é ampla e, segundo Greenberg e Mitchell (1994), o aspecto relacional deveria ser sempre considerado o maior foco das discussōes.

As conceituações para o termo são vastas, mas atualmente a ênfase tem estado na melhoria da qualidade das relações. Vorus e Wilson (2004) fazem uma revisão atual sobre o conceito de relação de objeto, falando da importância de estudar o modo como os sujeitos se relacionam com o mundo externo através de suas características internas.

A qualidade das relações é o que, na maioria das vezes, produz algum tipo de sofrimento às pessoas. $\mathrm{O}$ impacto dessas relações ocorre num primeiro momento em nível psíquico, das constituições internas, nos registros das relações objetais. Num segundo momento, podem atingir o campo somático, se não elaboradas no plano mental, no que McDougall (1978/1989) chamou de eclosões psicossomáticas, quando a vivência dos afetos pode ser tão desagregadora que exceda a elabora- 
ção psíquica. Segundo Moore e Fine (1990), objetos internos são representações intrapsíquicas das relações com o outro. No curso das relações objetais ocorre a internalização do objeto e seus atributos, e a internalização é um processo fundamental para o desenvolvimento da estrutura psíquica, já que é através dela que o sujeito vai gradualmente assumindo as funções originalmente supridas por outros.

Tais relações, ou, mais que isso, a forma como são registradas pode ter como resultado o adoecimento orgânico ou psicossomático, principalmente nas questões relativas ao adoecimento de pele, entendida como órgão de relação, fronteira entre mundo interno e mundo externo, eu e o outro.

\section{CORPO, ADOECIMENTO FÍsico E RELAÇÕES OBJETAIS}

A construção da teoria e o entendimento das relações objetais não pode deixar de passar pelo corpo, já que este é o local primeiro onde se estabelece o sentimento de ego. É através do corpo que o bebê conhece seu mundo, desde as primeiras experiências de contato no nascimento e na amamentação, e depois no conhecimento do ambiente e na fala. É através dele que o bebê internaliza os objetos primários, caracterizados como bons ou maus.

É sabido que, na vida adulta, quando da emergência de conflitos, tendemos a utilizar um funcionamento mais ou menos regressivo no enfrentamento da crise. Assim, não podemos desconsiderar o uso do corpo como veículo de expressão do sofrimento, quando circunstâncias internas ou externas ultrapassam os modos psicológicos de resistência habitual, além de ser o meio através do qual estabelecemos as relações. McDougall (1996) traz o adoecimento físico à cena psicanalítica, enfocando as possibilidades de analisabilidade de pacientes com transtornos ditos psicossomáticos. Consideraremos aqui uma visão atual de que todos nós, em algum momento, recorremos à saída psicossomática quando da impossibilidade de resolução do conflito em nível mental (Mello Filho, 2002). Especificamente, trataremos das funções da pele, do adoecimento crônico de pele como uma forma possivelmente regressiva de enfrentamento de tais conflitos, considerando a pele como o envoltório corporal e primeiro meio de contato com o mundo, através do outro e das relações com ele estabelecidas.

Em termos de psicopatologia, hoje, já são bastante claros os mecanismos mentais envolvidos, bem como as dinâmicas de adoecimento. McDougall (1996) afirma que nos estados psicossomáticos é o corpo que se comporta de maneira delirante, é o corpo que "enlouquece" (McDougall, 1996: 22). 


\section{O PROBLEMA EM ESTUDO: O ASPECTO RELACIONAL DA PELE}

Quase todas as contribuiçōes de Winnicott (1979/1983) descrevem a luta permanente do self entre uma existência individual, mas que ao mesmo tempo permita o estabelecimento de intimidade através da proximidade com um outro. Essa possibilidade vem, novamente, desde as primeiras relações objetais estabelecidas entre o bebê e sua mãe, ou figura de cuidado. Winnicott (1971/1975, 1987/ 1988) entende a separação da mãe como a única forma possível de união a um outro diferenciado. Questiona como, então, se dá o processo de a criança descobrir-se dentro dos cuidados de sua mãe sem perder-se nela. Salienta que a mãe também tem de dispor de recursos internos e ambientais para cumprir sua função de cuidado, permitindo a diferenciação. Ele cria o conceito de unidade mãe-bebê, a partir de sua experiência na pediatria, com a observação da relação mãe e criança, e afirma que o ponto de referência de estudo não devem ser os processos que ocorrem apenas dentro da criança, mas no campo relacional entre a criança e o cuidador.

Winnicott (1979/1983) estabelece as relações objetais em um plano separado dos processos instintivos. Para o autor, as primeiras relaçôes objetais são interações entre as necessidades desenvolvimentais da criança e os cuidados maternos oferecidos pela figura de cuidado, completamente separados de satisfação pulsional. $\mathrm{O}$ bebê necessita dos cuidados maternos que definem a maternidade/ maternagem suficientemente boa, o que inclui um ambiente de sustentação à díade. Para Winnicott, o selfsurge e é estruturado através de experiências relacionais com cuidados maternos específicos. Surge aqui a função de holding materno, que realiza as necessidades físicas e afetivas do bebê, promovendo a continência de seus impulsos agressivos.

Importante lembrar que nesse estágio inicial o bebê encontra-se em estado fusional com a mãe, incapaz de diferenciar objetos internos (que estão sendo introjetados) de objetos externos (ainda não reconhecidos como tal). Trata-se de um processo eminentemente relacional, que se dá através do contato e da elaboração de experiências inerentes à existência. $\mathrm{O}$ autor salienta que esses processos não são apenas fisiológicos, mas fazem parte da psicologia da criança e ocorrem determinados pela empatia materna. Através dessas relações e da qualidade destas, começa a se estabelecer o que Winnicott denominou de sentimento de ego, que levará o lactente ao que se pode chamar de estado unitário.

Winnicott denomina o início dessa integração como a chegada do lactente à existência psicossomática, a inserção da psique no soma. A base dessa inserção é a conjugação das experiências percebidas e sentidas com o novo estado de integração. 
Jeammet, Reynaud e Consoli (2000) afirmam que a pele tem uma função importante na formação da imagem corporal, também no sentimento de unidade da criança e na constituição de seu ego, sendo a pele uma forma sobre a qual se apoiaria o sentimento de ego.

Com esse desenvolvimento, Winnicott continua, colocando concretamente o papel da pele como uma membrana limite entre o eu e o não-eu - que ainda não é reconhecido como o outro, apenas como um objeto fora de mim -, denominando a pele de membrana do ego. A partir desse momento, o bebê passa a ter um interior e um exterior, a estruturação de um esquema corporal, tudo contido pela pele. Daqui surgirão os processos secundários e a função simbólica. Para o autor, na normalidade ocorre uma troca constante, à medida que a criança vive e coleta experiências, de modo que o mundo interno é enriquecido pelo que acontece no exterior, e a base disso é a incorporação e a eliminação de experiências através do corpo e da pele.

A pele é o principal meio de contato do sujeito com o mundo e, se não o principal, certamente o primeiro (Anzieu, 1989; Montagu, 1988; Volich, 2000; Winnicott, 1979/1983), uma interface entre eu e o outro, entre mundo interno e externo (Bitelman, 2003). Sabe-se que a pele tem a mesma origem embrionária que o sistema nervoso (Azambuja, 2000; Ballone, Netto \& Ortolani, 2002), o que permite iniciar a compreensão sobre como pode a pele, efetivamente, ser um importante meio de manifestação de conflitos internos do sujeito. Por conflitos internos aqui entenderemos algo proveniente das relaçôes do sujeito com seu ambiente, desde o início da vida, sobre a qualidade das internalizações de objeto e como se apresenta na vida adulta, em termos da relação com esses objetos.

As manifestações aparentes na pele não podem, em geral, ser disfarçadas: a emoção como manifestação física tem na pele um meio de expressão; os registros de experiências vividas estão ali colocados, na forma de cicatrizes; as lesões de uma doença marcam o espaço de uma ferida física e, por que não dizer, psíquica, tomando a pessoa como uma totalidade psicossomática.

São conhecidas as falas populares "à flor da pele", "é uma questão de pele", "estar na pele de alguém”, e outras, como afirma Neves (2003). A autora salienta os processos de identificação com o outro, contidas em tais falas, sendo, então, a pele uma camada externa do corpo que proporciona sentimentos do outro em relação ao si mesmo.

Outro ponto importante sobre a pele é que a partir e através dela iniciamos nosso contato com o mundo externo. Desde o momento do nascimento, a passagem do bebê pelo canal vaginal inaugura a série de contatos que fará no decorrer de seu desenvolvimento: a amamentação, os cuidados, toques, carinhos, até a 
diferenciação de si e do outro para a estruturação do ego. Segundo Winnicott (1988/1990), a pele tem a importância de conter a psique dentro do corpo, e isso se dá através do manuseio da pele no cuidado do bebê. Anzieu (1989) trata a pele com o que denominou de "envelope psíquico". Enuncia que as sensações cutâneas, mesmo antes do nascimento, introduzem as crianças num universo complexo, que tende a despertar suas percepçôes e a consciência tanto de movimentos internos quanto externos. Essas percepções subentendem o sentimento global de existir, acenando a possibilidade de um espaço psíquico originário.

Uma hipótese viável é que o adoecimento de pele esteja exatamente relacionado à dificuldade de limitaçõos entre o eu e o não-eu, descritas até aqui. Num desejo regressivo de retomada da relação fusional com a mãe, em que são experimentados sentimentos de unidade, cuja sensação se busca por toda a vida adulta repetir, de forma mais ou menos madura, nas relaçôes com os pares, em que se incluem todas as formas de relação.

A pele lesionada parece representar esse rasgo, esse corte marcadamente simbólico da ruptura com o outro fusionado, necessária para a continuidade do desenvolvimento psicológico saudável, que não conseguiu se estabelecer por completo. Anzieu ampliará esta idéia.

Sobre os aspectos psicológicos do processo de adoecimento, McDougall (1992; 1996) discorre sobre essa função integrativa psique-soma proveniente das relações iniciais entre mãe e filho. A autora põe em evidência as primeiras trocas desse par no surgimento do que chama de soluções psicossomáticas. Salienta que a mãe pode não ser capaz de atender às necessidades do filho por entraves internos ou questôes ambientais. Esse fato criaria no bebê um sentimento permanente de frustração e fúria impotente. Esse tipo de experiência poderia impeli-lo a "construir com os recursos de que dispóe maneiras radicais de se proteger de crises afetivas e do esgotamento que disso pode resultar" (McDougall, 1996: 39). Para a autora, essa forma de proteção estaria muito provavelmente ligada ao uso de defesas primitivas contra a emoção, mas muito mais direcionadas ao fenômeno psicossomático que psicótico, em alguns casos.

\section{Uma leitura do Eu-Pele}

Adentrando mais profundamente no universo da teoria psicanalítica no que tange à dermatologia, dentre os citados até agora, um autor importante é Didier Anzieu, com a obra $O$ Eu-Pele, publicada no Brasil em 1989. No decorrer da obra, Anzieu faz inferências importantes que convergem para as discussóes propostas até aqui. Postula uma dupla sustentação para o psiquismo: uma, sobre o corpo 
biológico, outra, sobre o corpo social (em relação com o ambiente). Ele coloca o Eu-Pele intencionalmente como uma metáfora em que caberiam todas as questôes referentes à construção do psiquismo como uma estrutura intermediária do aparelho psíquico: entre a mãe e o bebê, entre a inclusão mútua dos psiquismos na organização fusional primitiva e na diferenciação das instâncias psíquicas (Ego, Id, Superego). O autor reforça as idéias de Winnicott, afirmando que o holding seria também uma função biológica por estar ligado à forma como a mãe segura o corpo do bebê. Não importaria apenas a internalização do seio bom (objeto primário), mas da identificação primária de um suporte ao qual a criança se une e que a mantém, face a face, com o corpo.

Para o autor, a complexidade fisiológica das funçôes da pele antecipa a complexidade do eu no plano psíquico. Ele afirma que a pele é o mais vital dos órgãos dos sentidos, pois que se pode viver cego, surdo, sem paladar e sem olfato, mas sem a integridade da maior parte da pele não se sobrevive (Anzieu, 1989).

Anzieu não propõe uma teoria de relações objetais, mas, ao colocar a importância do desenvolvimento psíquico no holding materno, pressupõe a existência de tais relações mais focadas na que representa a pele como meio de relação.

A noção de Eu-Pele tem o sentido de entender como se formam os envelopes psíquicos, quais suas estruturas, seus encaixes, patologias e como, através do tratamento psicanalítico, podem ser reinstauradas as fronteiras no sujeito. Anzieu retoma a discussão apresentada por Winnicott e estabelece o Eu-Pele como um princípio de diferenciação interna e um princípio de contenção (ou de função continente, dito de outra forma). Anzieu cita Freud (1895) no artigo "Estudos sobre a histeria", no qual teria "pressentido" (Anzieu, 1989: 5) a formulação da hipótese de que a externalidade do corpo considera esse princípio de diferenciação interna um princípio de contenção, que seria depois desenvolvido pelos autores psicanalíticos.

Importante mencionar que o autor destaca principalmente o adoecimento psicológico quando fala em barreiras, limites e fronteiras psíquicas, citando as patologias de estado-limite (borderline), autismo e outras. Introduz a noção de "envelope psíquico", cuja metáfora de contenção é a pele, e define o "eu" como uma estrutura de envelope.

Quanto ao adoecimento da pele, Anzieu cita o arranhar-se como uma das formas arcaicas do retorno da agressividade sobre o corpo; as mutilações da pele, reais ou imaginadas, como tentativas dramáticas de manter os limites do corpo e do eu, de restabelecer o sentimento de estar intacto e coeso. As feridas apresentadas quando da existência de uma afecção de pele não poderiam acaso ser consideradas uma forma de mutilação, posta a característica auto-imune de algumas doenças de pele? 
Ainda sobre as afecções de pele, Anzieu afirma que estas mantêm estreita relação com os estresses da existência, com as crises emocionais, e ensaia empiricamente a hipótese colocada neste artigo e que considera seu principal propósito, que é a relação com as insuficiências da estruturação do eu no momento inicial do desenvolvimento. Afirma, deste modo, que as doenças de pele são decorrentes da patologia do apego (Anzieu, 1989).

$\mathrm{O}$ autor coloca uma dúvida que nos parece importante: a reação de uma pessoa sob a forma do adoecimento de pele seria uma exigência dirigida à necessidade do toque, ou a um modo, contrário, de isolamento? Pensamos que as duas necessidades podem estar contidas no adoecimento da pele, que não seriam excludentes uma da outra.

Por Eu-Pele, Anzieu compreende a representação que serve ao eu da criança durante as fases precoces do desenvolvimento, a partir das experiências da superfície do corpo. Corresponderia ao momento em que o eu psíquico se diferencia do eu corporal. Retorna a Freud e afirma que toda a atividade psíquica se estabelece sobre uma função biológica e explica como o Eu-Pele se estabelece, afirmando que encontra sua justificação nas funções da pele: a primeira seria a de uma bolsa que contém e retém em seu interior o bom armazenado, como a amamentação, os cuidados, as palavras; depois, teria a função de interface que marca o limite com o que está fora, barreira que protege das agressões de outros; a terceira função seria a de um meio de comunicação com os outros, de estabelecimento de relações significantes e, além disso, a de uma superfície de inscrição de traços deixados por tais relações.

Tentando encontrar respostas às proposições sobre o que se passaria no psiquismo de pessoas acometidas por doenças na pele, esse órgão de externalidade e internalidade, Anzieu vai à direção do que buscamos comprovar pela pesquisa: na observação de pacientes, estes apresentavam fantasias mais ou menos conscientes de fusão cutânea com a mãe. A união simbiótica com a mãe é representada no pensamento arcaico por uma imagem tátil em que dois corpos - da mãe e da criança - têm uma superfície comum, e a separação da mãe é representada pelo arrancar dessa pele comum. "Aquela que atende é a que esfola; mas aquela que rasgou o envelope comum é também a que pode repará-lo" (Anzieu, 1989: 47). Essa fantasia de uma pele comum é reavivada mais tarde pela experiência amorosa. Mãe e filho devem se encaminhar para um funcionamento cada vez mais separado, essa etapa requer o desaparecimento da pele comum e o reconhecimento de que cada um tem sua própria pele e seu próprio eu, o que não acontece sem resistência nem dor.

Anzieu inicia e termina o estudo do desenvolvimento psicológico tendo a pele como pano de fundo. Apresenta o que chamou de funçóes do Eu-Pele, que 
são nove, dentre as quais salientamos o aspecto auto-destrutivo da pele e do eu, pois, se não diferenciado da mãe, tende a voltar contra si a pulsão agressiva que teria a mãe como objetivo final, exatamente pelo processo de diferenciação. Como não reconhece o outro, volta contra si mesmo. $\mathrm{O}$ autor compara este processo com o funcionamento celular e com os estudos de imunologia, através dos fenômenos auto-imunes.

Na sua obra, Anzieu repassa as teorias de Freud, Klein, Winnicott e Bowlby em muitos momentos. Ele se fixa em Bowlby e nas questões do apego, em Winnicott e na questão do holding e amplia a discussão, afirmando que a problemática inconsciente do adoecimento da pele giraria em torno da proibição primária do tocar, nas formas de carência da carícia como uma proibição de se colar ao corpo do outro; a superestimulação de contatos maternos, por outro lado, ultrapassaria as fronteiras que se está tentando estabelecer no inicio do desenvolvimento do psiquismo, não permitindo o afastamento necessário para que se constitua o envelope psíquico que pertence ao bebê como propriedade particular. Ele considera que a gravidade da alteração da pele está em relação à importância quantitativa e qualitativa das falhas do Eu-Pele e cita um artigo em que afirma que a profundidade da alteração da pele é proporcional à profundidade do dano psíquico. Essa é a hipótese central com a qual trabalhamos neste artigo.

\section{A DisCUSSÃO DA PELE NA CONTEMPORANEIDADE}

Autores contemporâneos tratam do assunto de forma aplicada, tentando demonstrar como aparece, na prática, a conjugação de tais relações com o surgimento de afecçôes dermatológicas. Hisada (2000) afirma que os problemas de pele surgem por falta de contato físico com a mãe. Essa é uma formulação da autora com base na observação clínica. Relata que os pacientes com problemas dermatológicos apresentam um estado de dependência e insegurança em relação à mãe, e as mães apresentam personalidade ansiosa, são rejeitadoras ou superprotetoras, e dotadas de personalidade infantil, com hostilidade disfarçada em ansiedade. Seriam mães que não gostam do toque, privando seus bebês do contato cutâneo.

Questôes relativas ao desencadeamento das doenças de pele têm sido estudadas no exterior, e tais estudos têm sido pouco realizados no Brasil. Em termos de adoecimento de pele e relaçôes objetais, apenas um estudo italiano foi encontrado (Ventola, Sinisi, Robusti \& Rantuccio, 1986) e um brasileiro, enfocando uso de defesas em pacientes com psoríase (Catropa, 1986). A maior parte da literatura sobre psicologia e dermatologia versa sobre o tema do estresse, algumas vezes de 
forma isolada de outros processos fundamentais. Um dado importante sobre o desencadeamento das doenças de pele é a existência, permanente ou abrupta, de estressores, ambientais ou não.

O fator estressor externo é inegável e comprovado pela experimentação. Mas o que, em determinados sujeitos, estabelece o surgimento de uma dermatose, de uma manifestação cutânea, ao invés de uma outra manifestação somática? Onde estará colocada a necessidade de não esconder o conflito, deixá-lo à mostra e de, ao mesmo tempo, não obter meios de expressá-lo de outra forma? Este ensaio se propôs a levantar algumas possibilidades de resposta a essa questão.

Bria e Rinaldi (1999) falam da pele como uma metáfora do funcionamento da mente na qual as primeiras organizações psíquicas estão colocadas e através da qual se manifestam tais organizaçôes, por meio das experiências inicialmente difusas e gradativamente integradas. No estudo sobre estilos de apego e relação de objeto, frisam a importância das experiências de separação para pacientes com afecções cutâneas.

Sobre a importância do ambiente no desenvolvimento de doenças psicossomáticas, especificamente as de pele, Schachner (2003) afirma que o impacto de uma doença de pele em um membro da família é inegável, mas que é preciso ver como o ambiente pode ter estruturado a condição de adoecimento. Relaciona casos de dermatoses com privação de sono, mudanças nas rotinas familiares, prejuízo de socialização e perdas de forma geral, através da observação clínica.

Por fim, Lehtonen, Partanen, Purhonen e colaboradores (2006), num estudo finlandês experimental, verificaram as bases neurofisiológicas do cuidado ao bebê, considerando a questão da corporalidade do ego e enfatizando os afetos primitivos do período como sendo organizados pelo cuidado, através de experiências da superfície do corpo. São os estudos que verificam os construtos freudianos na contemporaneidade, aproximando a neurociência da psicanálise. Os autores fazem ainda uma revisão sobre a experiência corporal do ego como formador das primeiras representações mentais, em nível cerebral. Finalizam, afirmando que as relações objetais vêm sendo também estudadas em relação ao funcionamento cerebral.

\section{CONSIDERAÇÕES FINAIS}

Todos os autores aqui apresentados deixam claros os aspectos relacionais na formação da pessoa desde suas relações iniciais com as primeiras figuras de contato. Dados sobre psicopatologia foram excluídos desta apresentação, dado o conhecimento notório de suas relações com os modelos de relação objetal estabelecidos, mas já é consenso entre algumas vertentes teóricas que a psicopatologia é um 
fenômeno relacional, pois que onde haja esquizofrenia haverá certamente um outro e um ambiente facilitador do desenvolvimento da doença psíquica.

Assim, o adoecimento orgânico, ou o que se chama de transtorno psicossomático, poderia ter sua origem no estabelecimento de vínculos, no modo como se deram as internalizaçõos dos objetos e nos modelos particulares de relação objetal.

Autores como Winnicott, que dão bastante importância ao ambiente inicial, ou à matriz de identidade configurada quando do nascimento e desenvolvimento inicial da criança, frisam a importância das relações propriamente ditas, ou objetivamente percebidas, em termos de satisfação de necessidades para o desenvolvimento de uma personalidade saudável. McDougall enfoca a importância dos impulsos agressivos envolvidos no processo psicossomático, considerando as relações objetais e o retorno ao self de impulsos agressivos, que não podem ser dirigidos ao objeto, na fantasia de destruir os aspectos bons junto com os maus e aponta que a criança volta contra si tais impulsos em forma de culpa, o que geraria adoecimento. Anzieu traz o adoecimento de pele como que representando na superfície os conflitos de ordem interna; um funcionamento bastante primitivo em termos de organização defensiva e de modelos de relação objetal.

$\mathrm{O}$ adoecimento da pele é exposto, ele pede o contato e ao mesmo tempo o faz evitar. Essa complexidade é que tentamos abarcar com o entendimento do funcionamento psíquico nos termos da análise das relaçôes objetais.

\section{REFERÊNCIAS BIBLIOGRÁFICAS}

Anzieu, D. (1989). O Eu-Pele. São Paulo: Casa do Psicólogo.

Azambuja, R. D. (2000). Dermatologia integrativa: a pele em um novo contexto. Anais Brasileiros de Dermatologia, 75, 4, 393-420.

Ballone, G. J.; Neto, E. P. \& Ortolani, I. V. (2002). Da emoção à lesão: um guia de medicina psicossomática. São Paulo: Manole.

Bitelman, B. (2003). Pele. Em Volich, R. M.; Ferraz, F. C. \& Rocha, W. (Orgs.). Psicossoma III - Interfaces da psicossomática (pp. 353-357). São Paulo: Casa do Psicólogo.

Bria, P. \& Rinaldi, L. (1999). La pelle psichica: principi e prospettive d'intervento in psico-dermatologia. Clinica Terapeutica, 150, 4, 287-293.

Catropa, S. (1986). Organizações defensivas em pacientes com psoríase. Boletim de Psiquiatria, 19 (2), 27-27.

Freud, S. (1923). O ego e o id. Obras completas, ESB, v. XIX. Rio de Janeiro: Imago, 1976. Greenberg, J. R. \& Mitchell, S. (1994). Relaçôes objetais na teoria psicanalítica. Porto Alegre: Artes Médicas. 
Hisada, S. (2000). Transtornos psicossomáticos: uma visão winnicottiana. Revista Mudanças: Psicoterapia e Estudos Psicossociais, 8, 14, 81-88.

Jeammet, P.; Reynaud, M. \& Consoli, S. (2000). Psicologia Médica. São Paulo: MEDSI. Lehtonen, J.; Partanen, J.; Purhonen, M.; Valkonen-Korhonen, M.; Kononen, M.; Saarikoski, S. \& Launiala, K. (2006). Nascent body ego - metapsychological and neurophysiological aspects. International Journal of Psychoanalysis, 87, 1335-1353.

McDougall, J. (1978). Em defesa de uma certa anormalidade - teoria e clínica psicanalitica. Porto Alegre: Artes Médicas, 1989. . (1992). Teatros do Eu. Rio de Janeiro: Francisco Alves. . (1996). Teatros do corpo: o psicossoma em psicanálise. São Paulo: Martins Fontes.

Mello Filho, J. (2002). Concepção psicossomática: visão atual. São Paulo: Casa do Psicólogo. Montagu, A. (1988). Tocar - o significado humano da pele. São Paulo: Summus.

Moore, B. E. \& Fine, B. D. (Eds.). (1990). Psychoanalytic terms and concepts. New Haven: The American Psychoanalytic Association and Yale University Press.

Neves, S. M. (2003). Eu-pele, psicossomática e dermatologia. Em Volich, R. M.; Ferraz, F. C. \& Rocha, W. (Orgs.). Psicossoma III - Interfaces da psicossomática (pp. 359-369). São Paulo: Casa do Psicólogo.

Schachner, L. A. (2003). Skin disease, psyche and family. Dermatology Times - Health Module, 24, 6, 4.

Ventola, C.; Sinisi, D.; Robusti, G. \& Rantuccio, F. (1986). Indagine psicodiagnostica in pazienti psoriasici - studio con il Test delle Relazione Oggecttali di Phillipson. Giornale Italiano di Dermatologia e Veneorologia, 121, 2, 75-77.

Volich, R. M. (2000). Psicossomática: de Hipócrates à psicanálise. São Paulo: Casa do Psicólogo.

Vorus, N. \& Wilson, A. (2004). Conceptual frontiers: representation and object relations. International Journal of Psychoanalysis, 85, 1, 1501-1504.

Winnicott, D. W. (1971). O brincar e a realidade. Rio de Janeiro: Imago, 1975. - (1979). O ambiente e os processos de maturação - estudos sobre a teoria do desenvolvimento emocional. Porto Alegre: Artes Médicas, 1983. . (1987). Os bebês e suas mães. São Paulo: Martins Fontes, 1988. . (1988). Natureza humana. Rio de Janeiro, Imago, 1990.

Recebido em 6 de agosto de 2007 Aceito para publicação em 30 de novembro de 2007 